\title{
PERBEDAAN PROFIL LIPID DAN KADAR ASAM URAT PADA PASIEN DIABETES MELITUS TIPE II DENGAN DAN TANPA HIPERTENSI
}

\author{
Filliana Savitri, Intani Kurnia Savitri, Pugud Samodro, Lantip Rujito
}

Fakultas Kedokteran, Universitas Jenderal Soedirman, Jalan dr. Gumbreg No. 1 Purwokerto 53112

\section{ABSTRACT}

Diabetes mellitus type 2 is the 7 th world leading cause of death with the $95 \%$ proportion rate. Hypertension also correlates with this condition. The mortality of cardiovascular is 2-3 times higher for people with diabetes hypertension than people with diabetes normotension which caused by lipid and aciduric disturbations. This study was conducted using cross-sectional design. Samples of twenty-five individuals with diabetes normotension and 25 people with diabetes hypertension in Ajibarang Hospital of Banyumas district comply with inclusion-exclusion criteria were taken using continuous sampling technique. This study collected the total cholesterol and triglyceride data and analyzed with Mann-Whitney test. HDL cholesterol and LDL were also analyzed using T-test. This Study showed the average of total cholesterol of diabetics hypertension patients was $185.16 \pm 36.59$ and diabetics normotension patients was $196.76 \pm$ $44.62(\mathrm{p}=0.503)$. The average level of the triglyceride of diabetes hypertension patients was $181.76 \pm 72.68$ and diabetics normotension patients was $180.28 \pm 125.75(\mathrm{p}=0.367)$. The mean level of HDL cholesterol of diabetes hypertension patients was $39.12 \pm 11.07$ and diabetics normotension patients was $42.37 \pm 14.98(\mathrm{p}=0.387)$. Also, the average level of LDL of diabetes hypertension patients was $112.57 \pm 24.77$ and diabetics normotension patients was $118.33 \pm 37.41(\mathrm{p}=0.524)$. The average rate of uric acid of diabetes hypertension patients was $6.120 \pm 1.45$ and diabetics normotension patients was $5.768 \pm 2.45$ ( $p=0.200$ ). This study concluded, there was no significant difference in total cholesterol, triglyceride, HDL, LDL cholesterol, and uric acid of diabetics patient with or without hypertension in Ajibarang Hospital in 2016.

KEY WoRDS: Diabetes Mellitus, Hypertension, uric acid, lipid profile, LDL, HDL

\section{PENDAH UL UAN}

Diabetes melitus (DM) adalah kelompok penyakit metabolik yang ditandai dengan peningkatan kadar gula darah yang disebabkan adanya gangguan sekresi dan kerja insulin. Penyakit metabolik ini jika berlangsung kronik akan menyebabkan kegagalan berbagai organ terutama jantung, pembuluh darah dan saraf (American Diabetes Association, 2013) .

Menurut International Diabetes Federation (IDF) tahun 2013 prevalensi DM di dunia merupakan penyebab kematian urutan ketujuh dimana proporsi kejadian DM tipe II adalah 95\% dari total penderita DM di dunia. Prevalensi global DM tipe II akan mengalami peningkatan dari 171 juta orang pada tahun 2000 menjadi 366 juta orang pada tahun 2030 (International Diabetes Federation, 2013; Rathmann dan Giani, 2004)

Hipertensi merupakan penyakit yang sering menyertai penderita DM. Pada hipertensi sering terjadi abnormalitas lipid yang berkaitan dengan aktifitas saraf simpatis yang merupakan rangsangan dari resistensi insulin, selain itu hipertensi akan menurunkan aliran darah ke ginjal, sehingga menstimulasi reabsorpsi asam urat juga memperbesar risiko penyakit mikrovaskuler yang dapat memicu iskemia jaringan. Selanjutnya iskemia menyebabkan pelepasan laktat dan peningkatan produksi asam urat. Berdasarkan studi epidemiologi dilaporkan bahwa mortalitas kardiovaskuler 2-3 kali lebih tinggi pada penderita DM dengan hipertensi dibanding DM normotensi. Hal ini berhubungan dengan abnormalitas lipid dan abnormalitas asam urat pada kedua penyakit tersebut (Lee et al, 2015; Reaven et al,1996; Deedwania, 2011)
Berdasarkan penelitian sebelumnya yang dilakukan oleh Wijaya (2010), Noviyanti et al (2015), Ajuru (2013), dan Kodama et al (2009) mengatakan bahwa terdapat korelasi positif antara DM tipe II, abnormalitas lipid, asam urat dan hipertensi. Datadata tersebut diperoleh dari populasi dan etnis yang berbeda, untuk itu penelitian in bertujuan untuk mengkaji perbedaan profil lipid dan asam urat pada pasien DM tipe II dengan dan tanpa hipertensi pada subjek rumah sakit rujukan perifer.

\section{MET ODE}

Penelitian dilakukan di Poliklinik Penyakit Dalam dan laboratorium RSUD Ajibarang. Pelaksaan penelitian pada bulan Desember 2016. Data pasien yang terdiagnosis DM tipe II dengan hipertensi diperoleh dari rekam medis, kemudian pasien diperiksa profil lipid dan asam urat di laboratorium RSUD Ajibarang. Data tersebut merupakan data primer yang dilakukan melalui pemeriksaan klinis dan dilakukan oleh dokter serta tenaga medis yang kompeten. Penelitian ini menggunakan desain cross sectional. Data yang diperoleh kemudian diolah secara statistik. Analisis statistik yang digunakan adalah Fisher untuk data nominal, Saphiro Wilk untuk uji normalitas data dan Uji t tidak berpasangan untuk menilai perbedaan rerata dua kelompok, dengan tingkat bermakna $\mathrm{p}<0,05$.

\section{HASIL DAN PEMBAHASAN}

Jumlah responden pada penelitian ini didapatkan 25 pasien DM tipe II dengan hipertensi dan 25 pasien DM tipe II tanpa hiperetensi. Mayoritas responden perempuan lebih banyak dari laki-laki dengan persentase $88 \%$ pada DM tipe II dengan hipertensi dan $80 \%$ pada DM tipe II tanpa hipertensi, hasil uji parametrik didapatkan nilai $\mathrm{p}=0,702$. Berdasarkan karakteristik umur, mayoritas responden berusia $>45$ 
tahun lebih banyak daripada responden yang beusia < 45, dengan persentase pada DM tipe II dengan hipertensi sebesar 88\% dan DM tipe II tanpa hiperteni sebesar $84 \%$, dan pada uji parametrik didapatkan nilai $\mathrm{p}=0,448$. Sedangkan berdasarkan IMT, pada responden DM tipe II dengan hipertensi dengan IMT > 30 lebih banyak dengan persentase $40 \%$ dan pada DM tipe II tanpa hipertensi didapatkan IMT $<25$ berjumlah sama dengan IMT $>30$ dengan persentase $36 \%$, pada uji parametrik didapatkan nilai $\mathrm{p}=0,018$ (Tabel 1).

Tabel 1. Distribusi frekuensi, persentase, dan analisis bivariat pasien DM tipe II dengan dan tanpa hipertensi menurut jenis kelamin, umur dan IMT di RSUD Ajibarang

\begin{tabular}{lrrrr}
\hline Karakteristik & $\begin{array}{r}\text { DM Tipe II } \\
\text { HT }\end{array}$ & $\begin{array}{r}\text { DM Tipe II } \\
\text { Non HT }\end{array}$ & n (\%) & Nilai p \\
\hline Jenis kelamin & & \multicolumn{3}{c}{$0.702^{*}$} \\
Laki-laki & $3(12 \%)$ & $5(20 \%)$ & $8(16 \%)$ \\
Perempuan & $22(88 \%)$ & $20(80 \%)$ & $42(84 \%)$ \\
Rerata umur & $56.72 \pm 9.18$ & $54.80 \pm 8.52$ & 0.448 \\
$<45$ & $3(12 \%)$ & $4(16 \%)$ & $7(14 \%)$ \\
$>45$ & $22(88 \%)$ & $21(84 \%)$ & $43(43 \%)$ \\
Rerata IMT & $26.10 \pm 4.67$ & $23.02 \pm 4.15$ & $0.018^{*}$ \\
$<25$ & $7(28 \%)$ & $9(36 \%)$ & $16(32 \%)$ \\
$25-30$ & $8(32 \%)$ & $7(28 \%)$ & $15(30 \%)$ \\
$>30$ & $10(40 \%)$ & $9(36 \%)$ & $19(38 \%)$ \\
* perbedaan signifikan & &
\end{tabular}

Tabel 2. Analisis Bivariat Profil Lipid dan Asam Urat Pada Pasien DM Tipe II Dengan dan Tanpa Hipertensi

\begin{tabular}{lrrrr}
\hline Variabel & $\begin{array}{r}\text { DM HT (25) } \\
\text { Rerata } \pm \text { SD (mg/dL) }\end{array}$ & $\begin{array}{r}\text { DM Non HT (25) } \\
\text { Rerata } \pm \text { SD (mg/dL) }\end{array}$ & Nilai p \\
\hline Kolesterol total & $185,16 \pm 36,59$ & $196.76 \pm 44,62$ & 0,503 \\
Trigliserida & $181,76 \pm 72,68$ & $180.28 \pm 180,28$ & 0,357 \\
HDL & $39,12 \pm 11,07$ & $42.37 \pm$ & 14,98 & 0,387 \\
LDL & $112,57 \pm 24,77$ & $118.33 \pm$ & 37,41 & 0,524 \\
Asam Urat & $6,12 \pm 1,45$ & $5,76 \pm$ & 2,45 & 0,200 \\
\hline *perbedaan signifikan & & & &
\end{tabular}

Tabel 2. menjelaskan mengenai hasil analisis bivariat yang dilakukan. Hasil uji parametrik menunjukan bahwa tidak terdapat perbedaan rerata yang signifikan antara kadar kolesterol total $(p=0,503)$, trigliserida ( $p=357)$, kolesterol HDL $(p=0,387)$, kolesterol LDL ( $p=0,524)$, dan asam urat $(p=0,200)$ pada pasien DM tipe II dengan dan tanpa hipertensi.

Analisis terhadap karakteristik responden diperoleh hasil mayoritas jenis kelamin responden adalah perempuan (84\%). Hasil penelitian ini sejalan dengan Notoatmodjo (2003) bahwa perempuan memiliki risiko lebih besar mengidap diabetes melitus daripada laki-laki, hal ini dikarenakan beberapa sebab seperti faktor keturunan yang berhubungan dengan jenis kelamin atau perbedaan hormonal. Umur merupakan salah satu faktor risiko yang tidak dapat diubah namun memiliki hubungan yang erat dengan kejadian Diabetes Melitus tipe II. Prevalensi DM akan semakin meningkat seiring dengan meningkatnya umur hingga kelompok usia lanjut. Mayoritas responden berusia $>45$ tahun (86\%) hal ini sejalan dengan Rochmah (2006) bahwa seseorang yang telah mencapai umur 30 tahun kadar gula darahnya akan meningkat $1-2 \mathrm{mg} / \mathrm{dL} /$ tahun pada saat puasa dan meningkat 5,6-13 mg/dL/tahun pada 2 jam setelah makan. Mayoritas IMT responden adalah > 30 dengan jumlah 19 (38\%). Hal ini sejalan dengan penelitian Rabrusun (2014) yang menunjukan terdapat hubungan antara IMT dengan kejadian diabetes melitus tipe II.

Orang yang memiliki indeks massa tubuh obesitas lebih berisiko 7,14 kali untuk menderita Diabetes Melitus Tipe II dibandingkan dengan yang indeks massa tubuh normal (Trisnawati dan Soedijono ,2013). Hasil ini juga sejalan dengan penelitian yang dilakukan oleh Nguyen (2011) yang menyatakan bahwa indeks massa tubuh berhubungan dengan obesitas, semakin tinggi indeks massa tubuh semakin tinggi nilai gula darah puasanya.

Hasil analisis bivariat tidak terdapat perbedaan rerata yang signifikan antara kadar kolesterol total ( $p$ $=0,503)$, trigliserida $(\mathrm{p}=0,357)$, kolesterol HDL $(\mathrm{p}=$ $0,387)$, kolesterol LDL ( $\mathrm{p}=0,524)$, asam urat ( $\mathrm{p}=$ 0,200 ) pada pasien DM tipe II dengan dan tanpa hipertensi. Hasil dari penelitian ini tidak sesuai dengan teori yang menyatakan bahwa pasien diabetes dengan hipertensi cenderung mempunyai dislipidemia yang memiliki kadar LDL kolesterol, kolesterol total dan trigliserida yang tinggi, sedangkan kadar HDL yang rendah (Zeqollari et al, 2014). Diabetes dan hipertensi yang terjadi secara bersamaan berpengaruh pada dislipidemia yang lebih buruk dibanding ketika kedua penyakit tersebut terjadi secara terpisah (Isezuo et al, 2003).

Ketidaksesuaian hasil penelitian dengan beberapa teori bisa saja terjadi karena beberapa sebab seperti hanya satu kali pengukuran dan adanya variabel luar yang berpengaruh pada profil lipid yang tidak dikendalikan seperti konsumsi makanan, rokok, kontrol glikemik, dan obesitas serta variabel luar yang berpengaruh pada asam urat seperti konsumsi makanan dan minuman, dan obat penurun tekanan darah. Konsumsi serat makanan yang cukup dapat menurunkan kolesterol darah 10-15 persen. Beberapa jenis makanan lain justru meningkatkan kadar kolesterol seperti lemak sapi, makanan bersantan dan gorengan (Mamat, 2010; Hasneli et al, 2012). Selain konsumsi makanan, merokok pada pasien DM tipe II merupakan faktor tambahan yang berhubungan dengan plasma lipid (Adedeji. 2000). Pada orang-orang yang merokok, kolesterol HDL cenderung rendah yang artinya pembentukan kolesterol HDL yang bertugas membawa lemak dari jaringan ke hati terganggu. Selain itu, kontrol glikemik memiliki hubungan dengan profil lipid pada pasien DM tipe II, Kontrol glikemik secara tidak langsung juga berpengaruh terhadap penurunan HDL dan peningkatan kadar kolesterol melalui peningkatan trigliserida (Khan, 2007; Suastika, 2008).

Obesitas berpengaruh pula pada metabolisme lipid dalam tubuh, pada obesitas seringkali didapatkan hiperlipidemia. Asupan karbohidrat yang berlebih memicu hepar memproduksi VLDL dan sehingga terjadi peningkatan VLDL dan atau LDL pada individu 
yang obesitas sedangkan kolesterol HDL cenderung rendah pada orang obesitas (Rader dan Hoobs, 2005). Pada penelitian ini mayoritas responden memiliki IMT $>30$ (obesitas), namun rata-rata kadar kolesterol total, trigliserida, dan kolesterol LDL pada pasien DM tipe II dengan dan tanpa hipertensi menunjukan hasil yang masuk kategori normal meskipun kadar HDL pada pasien DM tipe II dengan hipertensi cenderung rendah, hal ini bisa saja berhubungan dengan kadar adiponektin yang tidak diperiksa oleh peneliti.

Kurangnya konsumsi air putih dan asupan purin dan fruktosa yang tinggi berpengaruh terhadap peningkatan asam urat, seperti makanan yang digoreng, santan, margarin atau mentega atau buahbuahan yang mengandung lemak tinggi seperti durian dan alpukat. Pada DM tipe II dan hipertensi yang terjadi secara bersamaan dapat berpengaruh terhadap peningkatan kadar asam urat. Hal ini dapat terjadi karena beberapa sebab seperti peningkatan retensi asam urat yang dipicu oleh agen diuretik penurun tekanan darah pada pasien DM dengan hipertensi. Adapun beberapa yang sering terlibat adalah diuretik, tiazid, furosemid, asam ethancrynic, etambutol dan aspirin dosis rendah (American Diabetes Association, 2013)

\section{KESIMPULAN DAN SARAN}

Tidak terdapat perbedaan kolesterol total, trigliserida, kolesterol HDL, kolesterol LDL dan asam urat yang signifikan pada pasien DM tipe II dengan dan tanpa hipertensi di RSUD Ajibarang Kabupaten Banyumas tahun 2016. Perlunya penelitian dengan populasi subjek dan cakupan area yang lebih luas.

\section{A F T AR REFERENS I}

Adedeji. 2000. Diet alcohol consumption, smoking and exercise as determinants of blood lipids levels of Nigeria. West African Journal Medicine. 19(4):283-285

American Diabetes Association. 2013. Diagnosis and Classification of Diabetes Mellitus. Diabetes Care. 36(Suppl 1):S67-S74.

Ajuru G. 2013. Studies on Uric Acid Level in Hypertensive and NonHypertensive Type 2 Diabetes Mellitus. International Journal of Diabetes Research, 2(6): 96-100

Deedwania P. 2011. Hypertension, dyslipidemia, and insulin resistance in patients with diabetes mellitus or the cardiometabolic syndrome: benefits of vasodilating betablockers. Journal Clinic of Hypertension (Greenwich). 13:52-9

Hasneli H, Kasmiyetti K, Umar HB. 2012. Hubungan Asupan Lemak, Asupan Serat Dengan Kadar Lipid Darah Serta Kaitannya Dengan Rasio Lingkar Pinggang-Lingkar Panggul Dosen Poltekkes Kemenkes RI Padang. Available online: poltekkespadang.ac.id/download1/al53.pdf

International Diabetes Federation, 2013. IDF Clinical Guidelines Task Force. Global Guideline for type 2 diabetes. International Diabetes Federation, 166 Chaussee de La Hulpe, B-1170, Brussels, Belgium.
Isezuo SA, Badung SL, Omotoso, AB. 2003. Comparative analysis of lipid profiles among patients with type 2 diabetes mellitus, hypertension and concurrent type 2 diabetes, and hypertension: a view of metabolic syndrome. Journal of the National Medical Association, 95(5):328-334.

Khan HA. 2007. Clinical significance of HbA1c as marker of circulating lipids in male and female type 2 diabetic patient. Acta diabetol (44):193

Kodama S, Saito K, Yachi Y, Asumi M, Sugawara A, Totsuka K, Saito A, Sone H. 2009. Association Between Serum Uric Acid and Development of Type 2 Diabetes. Diabetes Care. 32(9):17371742

Lee JJ, Ahn J, Hwang J, Han SW, Lee KN, Kim JB, Kim EJ. 2015. Relationship between uric acid and blood pressure in different age groups. Clinical Hypertension, 21, 14

Mamat. 2010. Faktor-faktor yang Berhubungan dengan Kadar Kolesterol HDL di Indonesia (Analisis Data Sekunder Ifls 2007/2008). Tesis. Pasca Sarjana Universitas Indonesia, Jakarta

Nguyen NT, Nguyen XT, Lane J, Wang P, 2011. Relationship Between Obesity and Diabetes in a US Adult Population: Findings from the National Health and Nutrition Examination Survey, 1999 2006. Obes Surgery 21:351-355.

Notoatmodjo S. 2010. Ilmu Kesehatan Masyarakat. Rineka Cipta, Jakarta.

Noviyanti F, Decroll E, Sastri S. 2015. Perbedaan Kadar LDLkolesterol Pada Pasien Diabetes Melitus Tipe II dengan dan Tanpa Hipertensi di RS Dr. M. Djamil Padang Tahun 2011. Jurnal Kesehatan Andalas. 4(2):545-550

Rabrusun, A. N. 2014. Hubungan Antara Umur dan IMT Dengan Kejadian Diabetes Mellitus Tipe 2 di Poliklinik Interna BLU RSUP Prof.Dr.R.D. Kandou. Manado : FKM Universitas Sam Ratulangi.

Rader DJ dan HH Hoobs. 2005. Disorders of lipoprotein metabolism. Dalam: Harrison's Principles of Internal Medicine. Edisi ke-16. New York: Mc Graw Hill; 2286-98.

Rathmann W dan Giani G. 2004. Global Prevalence of Diabetes: Estimates for the Year 2000 and Projections for 2030. Diabetes Care, 27:2568-2569

Reaven H, Lithell L, Lansberg. 1996. Hypertension and associated metabolic abnormalities : the role of insulin resistance and the sympathoadrenal system. The New England Journal of Medicine. 334:374-380

Rochmah W. 2006. Diabetes Melitus Pada Usia Lanjut, Buku Ajar Ilmu Penyakit Dalam, Edisi Ketiga, Editor Suyono S, 1857, Balai Penerbit FKUI, Jakarta

Suastika K. 2008. Dislipidemia pada Diabetes dan Sindrom Metabolik: Patogenesis dan Terapi, Dalam Kumpulan Naskah Ilmiah Obesitas, Sindrom Metabolik, Diabetes, Dislipidemia, Penyakit Tiroid. Bali: Udayana University Press. h. 220-225.

Trisnawati SK, Soedijono S. 2013. Faktor Risiko Diabetes Mellitus Tipe 2 di Puskesmas Kecamatan Cengkareng Jakarta Barat Tahun 2012. Jurnal Ilmiah Kesehatan. 5(1):611-615

Wijaya AA. 2010. Perbedaan Profil Lipid Pada Pasien Diabetes Melitus Tipe II dengan dan tanpa Hipertensi. skripsi. Universitas Negeri Surakarta

Zeqollari A, Spahiu K, Vyshka G, Cakerri L. 2014. Lipid Profile in Diabetes Mellitus Type 2 Patients in Albania and The Corellation with BMI, Hypertension, and Hepatosteatosis. Journal family medicin community health. 1(4):1018. 